\title{
Anaesthetic Considerations and Perioperative Features of Endoscopic Third Ventriculostomy in Infants: Analysis of 57 Cases
}

\author{
Infant Olgularnn Endoskopik Üçüncü Ventrikülostomi Işleminde Anestezi \\ ve Perioperatif Özellikler: 57 Olguluk Serinin Analizi
}

\author{
Dilek OZDAMAR ${ }^{1}$, Volkan ETUS ${ }^{2}$, Savas CEYLAN ${ }^{2}$, Mine SOLAK ${ }^{1}$, Kamil TOKER $^{1}$ \\ ${ }^{1}$ Kocaeli University, Faculty of Medicine, Department of Anaesthesiology, Kocaeli, Turkey \\ ${ }^{2}$ Kocaeli University, Faculty of Medicine, Department of Neurosurgery, Kocaeli, Turkey
}

Correspondence address: Volkan ETUS / E-mail: drvolkanetus@yahoo.com

\begin{abstract}
AIM: Endoscopic third ventriculostomy (ETV) is currently considered the best alternative to shunt systems in the treatment of triventricular hydrocephalus. However, there has been very few published data about the anaesthetic management and the complications of ETV procedure in infants. In this report, we detail our experience with 57 infants, who underwent ETV as an initial treatment for obstructive triventricular hydrocephalus between 2003 and 2010.

MATERIAL and METHODS: Anesthesia chart-records were retrospectively investigated and perioperative data were classified according to the stages of the procedure.

RESULTS: In this series, mean heart rate values showed a statistically significant difference in the period concerning the balloon dilatation of ventriculostomy orifice. An episode of bradycardia occurred in 2 patients during balloon dilatation. After the deflation of the balloon, bradycardia resolved immediately without administration of any medication. Video recordings of those two patients revealed that one of them had a narrow and opaque tuber cinereum, and the other had a shallow interpeduncular cistern.

CONCLUSION: During ETV procedure in infants, bradycardia may be a serious complication especially when performing balloon dilatation of the ventriculostomy orifice. We believe that close communication between the surgeon and the anaesthetist is extremely essential in this stage of the procedure.
\end{abstract}

KEYWORDS: Anesthesia, Bradycardia, Endoscopic third ventriculostomy, Infant

Öz

AMAÇ: Endoskopik üçüncü ventrikülostomi (ETV) günümüzde triventriküler hidrosefalinin tedavisinde şant cerrahisine en iyi alternatiftir. Ancak, bu işlemin infant yaş grubuna ait serilerdeki anestezi yönünden özelliklerini ve komplikasyonlarını tartışan yayınların sayısı son derece azdır. Bu çalışmada, 2003 ila 2010 seneleri arasında obstrüktif triventriküler hidrosefali tanısı ile primer işlem olarak ETV uygulanan 57 infant olgu serisinde bu yöndeki deneyimimiz sunulmuştur.

YÖNTEM ve GEREÇLER: Olgu serisinin anestezi kayıtları retrospektif olarak incelenmiş ve perioperatif veriler cerrahi prosedürün aşamalarına göre sınıflandırılarak değerlendirilmiştir.

BULGULAR: Olgu serisinde, ventrikülostomi ağzının balonla dilatasyonu safhasını içeren cerrahi periyodun kalp atım hızı açısından diğer periyodlardan anlamlı fark gösterdiği görülmüştür. Balon dilatasyonu safhasında 2 olguda bradikardi epizodu gözlenmiş olup, bu süreçler herhangi bir medikasyon gerektirmeden balonun indirilmesi ile birlikte sonlanmıştır. Bu olgulara ait cerrahi video kayıtları gözden geçirildiğinde; bir olguda dar ve opak tuber sinereum varlığı, diğerinde ise sığ interpedinküler sisterna yapısı olduğu dikkat çekmiştir.

SONUÇ: İnfantlardaki ETV işleminde, özellikle ventrikülostomi ağzının balonla genişletilmesi esnasında bradikardi ciddi bir komplikasyon olarak ortaya çıkabilir. Prosedürün özellikle bu aşamasında cerrah ve anestezistin dikkatli ve yakın işbirliği içerisinde olmalarının çok önemli olduğuna inanıyoruz.

ANAHTAR SÖZCÜKLER: Anestezi, Bradikardi, Endoskopik üçüncü ventrikülostomi, İnfant 


\section{INTRODUCTION}

Endoscopic third ventriculostomy (ETV) is currently considered the best alternative to cerebrospinal fluid shunt systems in the treatment of triventricular hydrocephalus. Although different opinions exist in the literature about the effectiveness of ETV in children under 1 year old $(2,7,19,23)$, there seems to be growing evidence that the success of ETV depends mainly on the etiology of the hydrocephalus and not on the age of the patient alone $(3,6,8,16,20,22)$. Because the anaesthesia for ETV procedure differs in many ways from conventional neurosurgical operations, anaesthesiologists are faced with the perioperative requirements and risks of this popular procedure. Intraoperative hemodynamic changes during ETV have been extensively studied with conflicting results. In a previous study, tachycardia was found to be more frequent than bradycardia and was attributed to an increase in intracranial pressure (ICP) and systemic hypertension (25). Obviously increasing ICP indefinitely may lead to cardiac arrest and bradycardia may be one of the first indicators of bending cardiac arrest during ETV. Leach et al. reported a profound bradycardia leading to a short-lived, spontaneously resolving episode of asystole in two occasions during ETV (25).

In the literature, there have been few publications about the anaesthetic management of ETV procedure, analyzing paediatric and adult patients together and in those reports the analyzed data included both paediatric and adult age groups $(5,10)$. This retrospective study is a unique report of the perioperative anaesthetic management of ETV procedure in paediatric patients younger than 1 year of age. We report our anaesthetic management experience on 57 infants, who underwent ETV as an initial treatment for triventricular hydrocephalus.

\section{MATERIAL and METHODS}

The study was approved by the University Institutional Research Board. The anaesthetic charts of the infants $(<12$ months of age) who underwent ETV as an initial treatment for triventricular hydrocephalus between February 2003 and September 2010 at our University Hospital were analyzed retrospectively. The data of 57 infants who met the following criteria were included in the study: (a) infants with primary congenital aqueductal stenosis, in whom the ETV procedure has been performed as an initial treatment for hydrocephalus; (b) infants with secondary aqueductal stenosis (due to all space-occupying lesions such as tumors and cysts in the third and fourth ventricles or within the cerebellum/ posterior fossa) in whom the ETV procedure has been performed as an initial treatment for hydrocephalus; (c) infants with infection related hydrocephalus in whom radiological examination showed a triventricular hydrocephalus indicating an obstructive component secondary to the history of CSF infection; (d) infants in whom hydrocephalus was accompanied by myelomeningocele and Chiari type 2 malformation; and (e) infants with post- hemorrhagic hydrocephalus, who were diagnosed as noncommunicating hydrocephalus because during imaging studies of flow dynamics, the site of obstruction seemed to be the aqueduct. The data of the endoscopic procedures with the following criteria were excluded from the study: (a) infection related or post-hemorrhagic hydrocephalus with ventricular compartmentalization or associate cystic lesions; (b) infants with triventricular hydrocephalus in whom the ETV procedure has been performed as an alternative treatment for the mechanical dysfunction of ventriculoperitoneal shunt; (c) infants in whom the ETV procedure has been performed before; (d) cases in which hydrocephalus was accompanied by congenital cardiovascular pathologies and (e) infants with the history of serious pulmonary problems.

Age, sex, ASA scores of the patients, premedication, duration of the anaesthesia and surgery, anesthetic drugs used, type of the irrigation fluid, and perioperative vital parameters of the patients (blood pressure, heart rate, body temperature, peripheral oxygen saturation and end-tidal $\mathrm{CO} 2$ ) were listed. Per operative and early postoperative complications were also listed.

In this study design, the video recordings of the 57 infants were reviewed and technical features, complications and the duration of endoscopic procedures were analyzed.

\section{Anaesthetic Management}

The same anesthetic method was used for all the patients in this series. None of the patients received premedication.

All patients were monitored with electrocardiogram (ECG), peripheral oxygen saturation $\left(\mathrm{SPO}_{2}\right)$, noninvasive blood pressure monitor, end-tidal $\mathrm{CO}_{2}\left(\mathrm{ETCO}_{2}\right)$ and body temperature via rectal route (RT) during the procedure. All patients received a $1 / 35 \%$ dextrose $+0.09 \% \mathrm{NaCl}$ infusion beginning from the commencement of anaesthesia until the end of the surgical procedure. Intraoperative fluid management was directed towards to maintain the normovolemic state. Anaesthesia was induced with sevoflurane inhalation, i.v bolus remifentanyl $0.5 \mu \mathrm{g} \mathrm{kg}^{-1}$ and i.v bolus mivacurium 0.2 $\mathrm{mg} \mathrm{kg}^{-1}$, and was maintained with 2-3\% Sevoflurane in 50 $\%$ air in oxygen. All patients were mechanically ventilated at pressure controlled mode with 8 to $10 \mathrm{~mL} \mathrm{kg-1}$ tidal volume with an appropriate rate to maintain the ETCO2 between 30-35 mmHg. Maintanance of the drug doses, i.v bolus $0.1 \mathrm{mg} \mathrm{kg}-1$ mivacurium, and $0.02 \mathrm{\mu g} \mathrm{kg}^{-1}$ remifentanyl was used. A heating blanket was used to prevent hypothermia during surgery. Paracetamol $25 \mathrm{mg} \mathrm{kg}^{-1}$ was given rectally for postoperative analgesia.

The data collected from the anaesthetic charts were analyzed at 7 periods: before induction (period 1), surgical incision (period 2), endoscopic exploration (period 3), perforation of the third ventricle floor (period 4), balloon dilatation (period 5 ), the end of skin closure (period 6), and after extubation (period 7). HR, SBP, DBP, ETCO2, SPO2 and RT values were listed according to these periods. 


\section{ETV Surgery}

Patients were selected for ETV procedure according to magnetic resonance imaging findings that suggested noncommunicating hydrocephalus with obstruction at or below the level of aqueductus Sylvii.

All ETV procedures have been performed with similar technique using "freehand method"by the same neurosurgeon (V.E). A 0 degree rigid rod lens neuroendoscope with an outer diameter of $4.0 \mathrm{~mm}$ (Karl Storz GmbH \& Co., Tuttlingen, Germany) has been used through a guiding tube. All operative procedures have been recorded by video imaging system (Karl Storz Telecam, SL). Ideally, the perforation in the floor of the third ventricle was made in the tuber cinereum between the infundibular recess of the pituitary stalk and the anterior border of the mammillary bodies. This allows entry into the interpeduncular cistern and avoids injury to the basilar apex. In our technique of performing ETV, we usually used the tip of the monopolar coagulating probe for making a blunt perforation in the floor and preferred not to make any coagulation unless we encountered a thick floor. The puncture site was dilated by inflating a 3-French double balloon catheter (Integra Neurosciences Inc., NJ, USA). Any thickened and diffuse arachnoidal trabeculations and webs in the interpeduncular cistern were eradicated successfully with blunt dissection until free communication along the basilar artery was visualized. Lactated Ringer's solution at 37 ${ }^{\circ} \mathrm{C}$ was used for irrigation. After the endoscopic procedure, all patients were followed in the postoperative care unit until they were transported to the ward.

\section{Statistical Analysis}

All of the data were expressed as means \pm standard deviation (SD). Perioperative SBP, DBP, HR, ETCO2, SPO2 and RT values were analyzed using repeated measures ANOVA and Bonferroni tests. $\mathrm{P}<0.05$ was regarded as statistically significant.

\section{RESULTS}

The anaesthetic charts, medical records and video recordings of 57 infants who underwent ETV as an initial treatment for non-communicating hydrocephalus were retrospectively analyzed. The ages of the patients were less than 12 months with the mean age of 8.3 months. Eleven patients were neonates ( $<1$ month). There were 31 girls and 26 boys. The ASA status of the patients were I or II. The mean anaesthesia time was $64.6 \pm 21.5$ minutes, and the mean duration of endoscopic procedure was $45.2 \pm 11.9$ minutes. The perioperative changes in HR, SBP, DBP, ETCO2, SPO2 and RT of the patients which were classified in seven periods are shown in Table I.

No significant difference was found in SBP, DBP, ETCO2, SPO2 and RT changes of the patients. However, mean HR values showed a statistically significant decrease $(p<0.05)$ in the balloon dilatation time period (period 5). The perioperative HR values were further analyzed according to the subgroups with different etiologies of the hydrocephalus. Patients were divided into five major groups according to the etiology of hydrocephalus: (a) primary aqueductal stenosis; (b) secondary aqueductal stenosis (all space-occupying lesions such as tumors and cysts in the third and fourth ventricles or within the cerebellum/ posterior fossa); (c) infection related hydrocephalus; (d) post-hemorrhagic hydrocephalus; and (e) myelomeningocele related hydrocephalus. The statistical analysis revealed that, in the balloon dilatation period (period 5) the mean HR values were significantly lower in "infection related hydrocephalus", "post-hemorrhagic hydrocephalus" and "myelomeningocele related hydrocephalus" subgroups without any accompanying significant changes in SBP and DBP values. However, in subgroups "primary aqueductal stenosis" and "secondary aqueductal stenosis", the mean HR values showed no significant difference among the seven periods of the surgical procedure. The perioperative changes in mean HR values of the subgroups with different etiology of hydrocephalus are summarized in Table II.

Table I: The perioperative changes in noninvasive systolic blood pressure (SBP), noninvasive diastolic blood pressure (DBP), peripheral oxygen saturation (SPO2), end-tidal CO2 (ETCO2), heart rate (HR), and body temperature via rectal route (RT) values of the patients are summarized in the table. SBP (in $\mathrm{mm} \mathrm{Hg}$ ), DBP(in mm Hg), SPO2 (\%), ETCO2 (in mm Hg), HR (in number of beats per minute) and RT (in degrees Celsius) values of the cases are shown in seven periods, representing the seven stages of the surgical procedure namely; before anesthesia induction (Period 1), during surgical incision and burr hole preparation (Period 2), during endoscopic exploration (Period 3), during perforation of the third ventricle floor (Period 4), during balloon dilatation (Period 5), at the end of skin closure (Period 6), and after extubation (Period 7). The values shown in the table are expressed as mean \pm standard deviation.

\begin{tabular}{|l|c|c|c|c|c|c|}
\hline Periods & $\begin{array}{c}\text { SBP } \\
\mathrm{mm} \mathrm{Hg}\end{array}$ & $\begin{array}{c}\text { DBP } \\
\mathrm{mm} \mathrm{Hg}\end{array}$ & $\begin{array}{c}\text { SPO2 } \\
\%\end{array}$ & $\begin{array}{c}\text { ETCO2 } \\
\mathrm{mm} \mathrm{Hg}\end{array}$ & $\begin{array}{c}\text { HR } \\
\text { BPM }\end{array}$ & $\begin{array}{c}{ }^{\circ} \mathrm{C} \\
\text { Period 1 }\end{array}$ \\
\hline Period 2 & $93.9 \pm 13.4$ & $56.5 \pm 9.1$ & $98.96 \pm 0.8$ & $29.7 \pm 3.4$ & $137 \pm 14$ & $36.5 \pm 0.2$ \\
\hline Period 3 & $88.6 \pm 14.2$ & $52.2 \pm 7.8$ & $98.80 \pm 0.6$ & $29.7 \pm 4.2$ & $136 \pm 13$ & $36.0 \pm 0.5$ \\
\hline Period 4 & $87.5 \pm 15.4$ & $51.6 \pm 8.8$ & $98.88 \pm 0.8$ & $29.9 \pm 4.4$ & $138 \pm 12$ & $35.9 \pm 1.1$ \\
\hline Period 5 & $91.2 \pm 13.9$ & $53.2 \pm 5.9$ & $97.90 \pm 5.8$ & $29.8 \pm 3.2$ & $123 \pm 14 *$ & $35.5 \pm 1.4$ \\
\hline Period 6 & $89.1 \pm 12.4$ & $52.1 \pm 7.6$ & $99.30 \pm 0.5$ & $30.2 \pm 4.2$ & $131 \pm 11$ & $35.2 \pm 0.6$ \\
\hline Period 7 & $95.1 \pm 15.8$ & $57.8 \pm 7.1$ & $99.51 \pm 0.7$ & $30.1 \pm 3.8$ & $134 \pm 10$ & $35.4 \pm 0.5$
\end{tabular}

$* p<0,05$ 
An episode of bradycardia (heart rate $<100$ beats per minute) occurred only in 2 of the 57 patients during the dilatation of ventriculostomy orifice. HR decreased to 94 beats per minute in the first case (in the subgroup of "infection related hydrocephalus") and 89 beats per minute in the second case (in the subgroup of "myelomeningocele related hydrocephalus"). In both of the cases, bradycardia lasted for less than 30 seconds and resolved immediately after the deflation of the balloon. There was no need for any medication in both cases. The duration of the endoscopic procedure was 41 minutes for the first case and was 44 minutes for the second case.
When the video recordings of endoscopic procedure of those two patients were reviewed, it was noticed that the first case had a narrow and opaque tuber cinereum (Figure 1A), and the second one had a very shallow interpeduncular cistern (Figure 1B). No surgical complication, i.e. mechanical neural tissue injury o necessitating vigorous irrigation was encountered in those two cases.

In our series, 3 cases (5.2\%) required ventriculoperitoneal (VP) shunting in the same session for the reason that ETV have not provided sufficient bypass for the cerebrospinal fluid due to distorted anatomy. Five patients (8.7\%) developed

Table II: The perioperative changes in heart rate (HR) values of the subgroups with different etiology of hydrocephalus are shown in seven periods, representing the seven stages of the surgical procedure namely; before anesthesia induction (Period 1), during surgical incision and burr hole preparation (Period 2), during endoscopic exploration (Period 3), during perforation of the third ventricle floor (Period 4), during balloon dilatation (Period 5), at the end of skin closure (Period 6), and after extubation (Period 7). HR is expressed in number of beats per minute (BPM) and the values shown in the table are expressed as mean \pm standard deviation.

\begin{tabular}{|c|c|c|c|c|c|c|c|}
\hline \multirow{2}{*}{ Etiology of Hydrocephalus } & \multicolumn{7}{|c|}{ Mean Heart Rate Values (BPM) in the Periods of Surgery } \\
\hline & Period 1 & Period 2 & Period 3 & Period 4 & Period 5 & Period 6 & Period 7 \\
\hline Primary aqueductal stenosis & $141 \pm 16$ & $142 \pm 14$ & $139 \pm 17$ & $140 \pm 13$ & $134 \pm 14$ & $136 \pm 11$ & $137 \pm 11$ \\
\hline $\begin{array}{l}\text { Secondary aqueductal stenosis due } \\
\text { to space-occupying lesions such } \\
\text { as tumors and cysts in the third } \\
\text { and fourth ventricles or within the } \\
\text { cerebellum/ posterior fossa }\end{array}$ & $136 \pm 15$ & $140 \pm 13$ & $138 \pm 15$ & $139 \pm 12$ & $135 \pm 16$ & $137 \pm 13$ & $136 \pm 10$ \\
\hline $\begin{array}{l}\text { Myelomeningocele-related } \\
\text { hydrocephalus }\end{array}$ & $138 \pm 14$ & $136 \pm 11$ & $135 \pm 11$ & $138 \pm 17$ & $* 117 \pm 13$ & $130 \pm 12$ & $134 \pm 10$ \\
\hline Infection-related hydrocephalus & $137 \pm 15$ & $135 \pm 10$ & $133 \pm 9$ & $136 \pm 10$ & $* 114 \pm 12$ & $127 \pm 8$ & $132 \pm 9$ \\
\hline Post-hemorrhagic hydrocephalus & $134 \pm 12$ & $137 \pm 12$ & $135 \pm 13$ & $137 \pm 11$ & $* 115 \pm 14$ & $125 \pm 9$ & $131 \pm 9$ \\
\hline
\end{tabular}

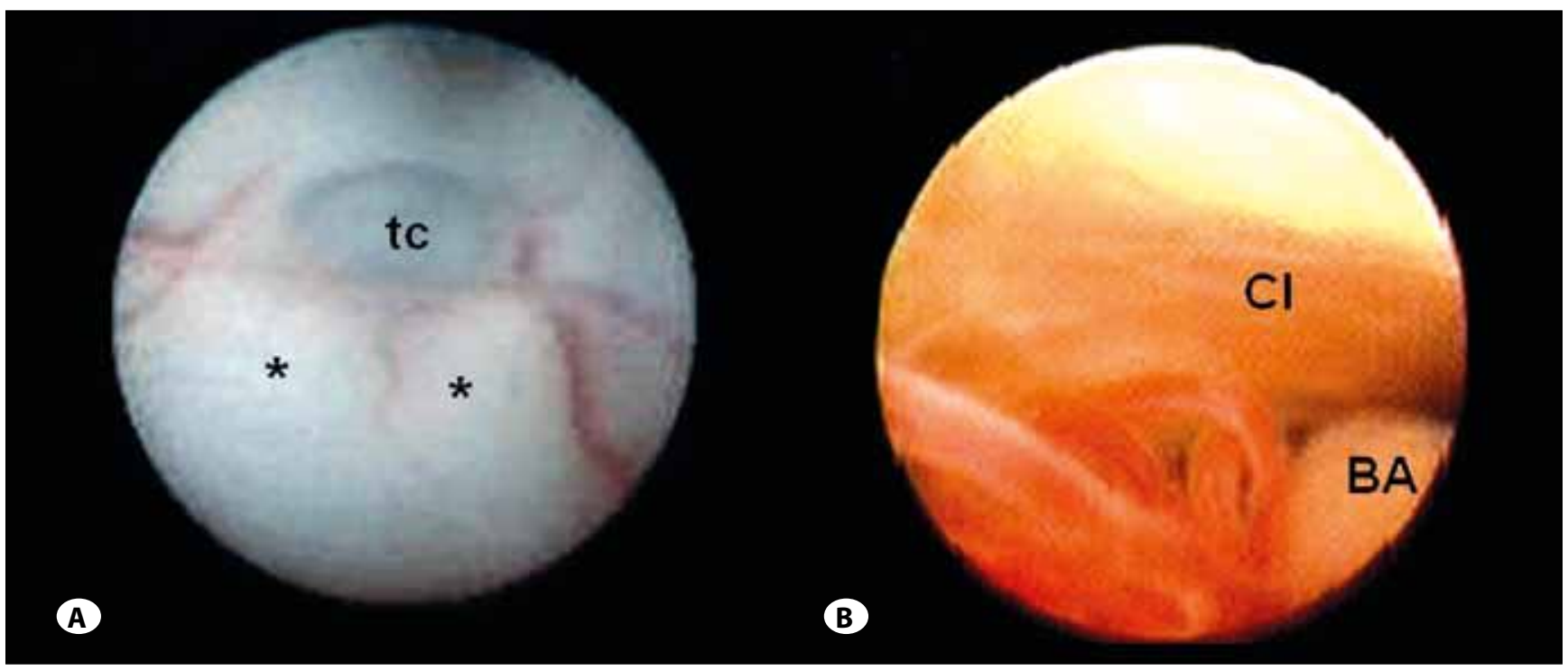

Figure 1: Neuroendoscopic views of the two patients in whom an evident episode of bradycardia was encountered during the balloon dilatation of the ventriculostomy orifice. A) Neuroendoscopic view of the third ventricle floor in the first case. A narrow and non-transparent tuber cinereum (tc) is seen anterior to the mamillary bodies (stars). B) Neuroendoscopic view through the narrow interpeduncular cistern of the second case. Note the close proximity of the basilar artery (BA) and clivus (Cl). 
mild venous bleeding during ETV, which was controlled with irrigation in all cases.

All of the infants were extubated at the end of anaeshesia and transferred to the recovery room and were also transferred to the surgical ward without any early postoperative complication.

\section{DISCUSSION}

ETV combines a minimally invasive approach with a visual control of manipulations, and is currently considered the best alternative to cerebrospinal fluid shunt systems in the treatment of triventricular hydrocephalus. Many authors have reported that success with ETV in the treatment of hydrocephalus depends largely on appropriate patient selection $(16,18,19,22,23)$. One of the controversial issues on performing ETV in the pediatric population is age. The question whether infants and very young children have a higher risk of treatment failure after ETV than older children is still being debated. In their study Cinalli et al. have shown that ETV could be successfully performed even in patients less than 6 months old (8), even though this young age was previously considered a contra-indication (25). In their study Gorayeb et al. reported a success rate of $64 \%$ in children younger than 1 year of age, who have undergone ETV for obstructive hydrocephalus and they advocated the use of ETV, when appropriate, regardless of age younger than 1 year (20). Also, to our experience, the success of ETV is etiology related rather than age-dependent. Our center has published a success rate of $56 \%$ in patients under 2 years of age. In this study, the analysis of the results in subgroups with different etiologies of the hydrocephalus showed that the success rates of ETV differed remarkably between different etiologies of hydrocephalus (16).

Despite the growing evidence that ETV can be successfully performed in infants, there exist only few publications about the anaesthetic management and the complications of ETV procedure in infantile age group $(5,10,13)$. Characteristics of neonates and infants are different from older children and adult patients. The main differences are lower blood pressure, faster heart rate, faster respiratory rate, lower lung compliance and higher ratio of body surface area to body weight. When ETV procedure is performed in hydrocephalic infants, anaesthesiologists are confronted with additional perioperative requirements and risks such as limited cardiac and thermoregulation reserves. In the present study, the features and perioperative complications of ETV procedure in infantile age group were discussed by analyzing the data of 57 infants.

The main goals of neuroendoscopic anaesthesia are a careful preoperative evaluation and a proper anesthetic plan, which allow precise cerebral haemodynamic control and rapid postanaesthetic emergence for early neurological assessment.

In his report, El-Dawlatly has suggested that premedication can be banned in ETV procedure to avoid oversedation and prolonged recovery because of the short duration of this surgical procedure (11). In our series, we also did not give any premedication to the cases. We used sevoflurane inhalation anaesthesia for the induction of anaesthesia.

The age-specific bolus dose of remifentanil has been shown to facilitate tracheal intubation with or without the use of neuromuscular blocking agents (21). Remifentanil, as a short term acting opioid, has also gained popularity in pediatric cases recently $(4,9,27,28,29)$. For this reason we preferred remifentanil for the induction of anaesthesia as many authors did in the recent years. Remifentanil also provides an easy titration of analgesia with haemodynamic stability and prompt recovery allowing early neurological assessment which are the fundamental goals of the neuroanaesthetic management.

As in the vast majority of intracranial procedures, in ETV procedure, nitrous oxide $\left(\mathrm{N}_{2} 0\right)$ has also been suggested to avoid because of the potential possibility of rising intracranial pressure and of the risks for pneumoencephalus and pneumoventricle (4)

Another important issue in ETV procedure is the necessity of adequate muscle relaxation. As a rule, under no circumstances should the patient move intraoperatively because any movement with the endoscope in place could cause misdirection and serious neurological or neurovascular damage. In our cases we preferred mivacurium as muscle relaxant and used additional doses when needed.

Concerning the perioperative complications of ETV procedure, bradycardia or other types of cardiovascular responses are frequently discussed in the literature $(5,10,12,17,25,26,30)$.

In their study, Van Aken et al. have shown that tachycardia was more frequent than bradycardia and this was attributed to an increase in intracranial pressure (ICP) and systemic hypertension, which has been caused by high-speed fluid irrigation (30).

El-Dawlatly reported an incidence of $41 \%$ bradycardia during ETV, which was attributed to stimulation of the floor of third ventricle with the tip of the neuroendoscope (15).

Baykan et al, reported bradycardia intraoperatively alone in $28.1 \%$ of their cases and the rates for asystole and for bradycardia following tachycardia was repoted as $0.5 \%$ and $12.4 \%$ respectively (5). Derbent et al, encountered bradycardia in only 1 of the 24 patients for a short period during balloon inflation with possible temporary brain stem ischemia and subsequent bradycardia (10).

In this study, statistically significant decrease in the mean $\mathrm{HR}$ values of the specific case groups (cases with "infection related hydrocephalus", "post-hemorrhagic hydrocephalus" and "myelomeningocele related hydrocephalus") unique to the balloon dilatation period is noteworthy. However, no significant difference in the mean SBP and DBP values was found in this period. This result may be interpreted as a mild bradycardia-inducing effect of the balloon inflation without 
creating a significant haemodynamic imbalance in infants during ETV. To our experience, tuber cinereum is usually non-transparent in post-infective or post-hemorrahgic triventricular hydrocephalus cases and generally it shows resistance to perforation and balloon dilatation. Also the infants with myelomeningocele related hydrocephalus, frequently show anomalies of the third ventricle floor such as narrow, opaque or parenchymatous tuber cinereum or small anterior chamber of the third ventricle as well as a shallow prepontine cistern configuration. We suggest that, in those case groups, it may be easier for the third ventricle floor and the contents of the interpeduncular cistern to undergo a temporary ischemia due to reduced regional cerebral perfusion or due to direct mechanical pressure during the balloon dilatation period. Besides this, an evident episode of bradycardia was encountered in two infants during the balloon dilatation of the ventriculostomy orifice in those case subgroups. In both cases bradycardia had resolved immediately after deflating the balloon without administration of any medication. When ETV video recordings of those two patients were reviewed, we have noticed that one of them (a case with infection related hydrocephalus) had a quite narrow and opaque tuber cinereum, and the other (a case with myelomeningocele related hydrocephalus) had a shallow interpeduncular cistern.

The central nervous system plays a crucial role in regularization of vasomotor tone and cardiac function. Medulla oblongata, where the dorsal vagal nucleus and parasympathetic preganglionic neurons are embedded, is involved in cardiovascular function. The function of the dorsal vagal nucleus may indirectly be influenced by descending autonomic pathways that travel through the midbrain and pons or by supranuclear modulation from hypothalamic centers (5). We suggest that, especially in cases with a narrow or tough tuber cinereum or a shallow interpeduncular cistern configuration, the third ventricle floor and the contents of the interpeduncular cistern seem to be easily affected during the balloon dilatation period and may promote an indirect parasympathetic activity, which results in bradycardia. To our experience, the cooperation of the neuroanaesthetist and the neurosurgeon during this stage of the ETV procedure is of extreme importance. Just before performing the balloon dilatation, the neurosurgeon should inform the anaesthetist about the anatomical features of the third ventricle floor and about the interpeduncular cistern if possible. Also the neuroanaesthetist should warn the surgeon immediately in case of bradycardia or other types of cardiovascular responses.

In ETV procedure, a vigorous irrigation may result in a sharp rise in the third ventricular pressure or may cause a local distortion of the autonomic nuclei of the hypothalamus. Pressure changes at the midbrain and the hypothalamus are believed to produce alterations in autonomic outflow, which consequently may contribute to the development of haemodynamic changes (2). In our series we did not experience any haemodynamic complications in those stages of the procedure. In our routine practice of ETV procedure we seldom use high-speed fluid irrigation and we try to avoid an increase in intraventricular pressure by admitting free outflow of the irrigant through the outflow tube. In their report ElDawlatly et al. described in detail a method for measuring third ventricle pressure during ETV and they found a negative correlation between third ventricle pressure and heart rate changes during ETV. In the same study they reported bradycardia in 6 of 14 patients and they have described their direct management of intraoperative bradycardia during ETV by withdrawing the scope away from the floor of the third ventricle (14). In another study, they reported bradycardia in 20 of 49 patients (13).

Aside from third ventricular pressure or stimulation of the floor of the third ventricle by the tip of the endoscope, the composition of the irrigation fluid is also important during ETV. It has been shown that irrigation of the ventricles with saline produces a marked hypertension, causing bradycardia by the pressor reflex (30). This could explain why El-Dawlatly et al. experienced a relatively high rate of bradycardia in their series, as they used saline irrigant $(13,14)$. A balanced electrolyte solution such as Ringer lactate has reported to be a better choice as compared to saline, because it caused only a mild temporary hypotension (30). We used Lactated Ringer's solution at $37{ }^{\circ} \mathrm{C}$ for irrigation and a low rate of bradycardia $(4.4 \%)$ in our series seems to support this data. We do recommend the use of Lactated Ringer's solution as infusate fluid and especially at $37^{\circ} \mathrm{C}$ to prevent hypothermia in infants.

\section{CONCLUSION}

As neurosurgeons continue to gain experience with ETV, the indications for this procedure are constantly being reviewed and expanded. Since there is growing evidence that ETV can be successfully performed in infants with triventricular hydrocephalus, the number of centers performing ETV in infantile age group is increasing. Thus the anaesthesiologists are being confronted with specific perioperative requirements and risks in this age group. However, there exist only few authentic publications about the anaesthetic management and the complications of ETV procedure in infantile age group. With the increasing interest in ETV, it is important to understand the physiological changes that occur during this procedure. Especially the autonomic changes are extremely important to the neuroanaesthetist. In this study, we report our experience on 57 infants. To our experience, the following issues should be taken into consideration by the anaesthesiologists who would be involved in conducting ETV procedure in this age group:

- Hydrocephalic infants need special considerations regarding the head size and anatomical landmarks of their airways. Especially in cases, in which the hydrocephalus is accompanied with other congenital malformations (neural tube defects, Dandy-Walker malformation) anatomical structure of the airways should be examined carefully before the operation. 
- Most of these patients have raised ICP, therefore all measures that avoid an excessive rise of ICP should be considered. Nitrous oxide is preferably avoided because of the potential possibility of rising ICP, pneumocephalus and pneumoventricle.

- As a general principle, under no circumstances should the patient move intraoperatively because any movement with the endoscope in place could cause misdirection and serious neurological damage. A non-depolarizing and "intermediate action" type muscle relaxant should be used to facilitate endotracheal intubation and to ensure immobilization of the infant intraoperatively. Especially in cases, where the intraventricular anatomical landmarks are distorted or the floor of the third ventricle is abnormal, the endoscopic procedure may take longer time because of the difficulty in gaining orientation or of some minor complications such as venous bleeding or minor parenchymal injury. In post-infective or posthemorrhagic triventricular hydrocephalus cases tuber cinereum is usually non-transparent and may show resistance to perforation and dilatation. Also, the interpedincular cistern may often present multiple and tough arachnoidal webs in these cases, which means that the neurosurgeon requires additional time for eradicating those membranes successfully with blunt dissection until free communication along the basilar artery is visualized. In such circumstances the duration of the procedure may go longer, so we strongly suggest a close communication between the neurosurgeon and the anaesthetist for the use of additional muscle relaxant doses.

- We believe that close communication between the neurosurgeon and the anaesthetist is extremely essential in certain stages of the ETV, such as perforation and balloon dilatation of the tuber cinereum, while performing this procedure in infants. One should also keep in mind that, especially the infants with infection related hydrocephalus, post-hemorrhagic hydrocephalus or myelomeningocele related hydrocephalus seem to have predisposition to show a decrease in heart rate during the balloon dilatation of the ventriculostomy orifice or may even develop bradycardia. We recommend that anaesthesiologists rigorously monitor cardiovascular changes and strict vigilance should be maintained for immediate detection of bradycardia.

- Although, using proper anesthetic management and surgical techniques minimalize the complications and makes ETV procedure considerably safe in infantile patient population, we advise to perform these procedures in centers where neonatal and pediatric intensive care units are available.

\section{REFERENCES}

1. Alvarez JA, Cohen AR: Neonatal applications of neuroendoscopy. Neurosurg Clin N Am 9: 405-413, 1998

2. Ambesh SP, Kumar R: Neuroendoscopic procedures: Anesthetic considerations for a growing trend. J Neurosurg Anesthesiol 12: 262-270, 2000

3. Balthasar AJ, Kort H, Cornips EM, Beuls EA, Weber JW, Vles JS: Analysis of the success and failure of endoscopic third ventriculostomy in infants less than 1 year of age. Childs Nerv Syst 23: 151-155, 2007

4. Batra YK, Al Qattan AR, Ali SS, Qureshi MI, Kuriakose D, Migahed A: Assessment of tracheal intubating conditions in children using remifentanil and propofol without muscle relaxant. Paediatr Anaesth 14: 452-456, 2004

5. Baykan N, Isbir O, Gercek A, Dagcinar A, Ozek MM: Ten years of experience with paediatric neuroendoscopic third ventriculostomy: Features and perioperative complications of 210 cases. J Neurosurg Anesthesiol 17: 33-37, 2005

6. Beems T, Grotenhuis JA: Is the success rate of endoscopic third ventriculostomy age-dependent? An analysis of the results of endoscopic third ventriculostomy in young children. Childs Nerv Syst 18: 605-608, 2002

7. Buxton N, Macarthur D, Mallucci C, Punt J, Vloeberghs M: Neuroendoscopic third ventriculostomy in patients less than 1 year old. Pediatr Neurosurg 29: 73-76, 1998

8. Cinalli G, Sainte-Rose C, Chumas P, Zerah M, Brunelle F, Lot $G$, Pierre-Kahn A, Renier D: Failure of third ventriculostomy in the treatment of aqueductal stenosis in children. J Neurosurg 90: 448-454, 1999

9. de Resende MA, da Silva EV, Nascimento OJ, Gemal $A E$, Quintanilha G, Vasconcelos EM: Total intravenous anesthesia (TIVA) in an infant with Werdnig-Hoffmann disease. Case report. Rev Bras Anestesiol 60: 170-175, 2010

10. Derbent A, Ersahin Y, Yurtseven T, Turhan T: Hemodynamic and electrolyte changes in patients undergoing neuroendoscopic procedures. Childs Nerv Syst 22: 253-257, 2006

11. El-Dawlatly A, Elgamal E, Murshid W, Alwatidy S, Jamjoom Z, Alshaer A: Anesthesia for third ventriculostomy. A report of 128 cases. Middle East J Anesthesiol 19: 847-857, 2008

12. El-Dawlatly AA, Murshid W, Alshimy A, Magboul MA, Samarkandi AH, Takrouri MS: Arryhthmia during neuroendoscopic procedures. J Neurosurg Anesthesiol 13:57-58, 2001

13. El-Dawlatly AA, Murshid WR, Ashimy A, Magboul MA, Samarkandi A, Takrouri, MS: The incidence of bradycardia during endoscopic third ventriculostomy. Anesth Analg 91: 1142-1144, 2000

14. El-Dawlatly AA, Murshid W, El-Khwsky F: Endoscopic third ventriculostomy: A study of intracranial pressure vs. haemodynamic changes. Minim Invasive Neurosurg 42: 198-200, 1999

15. El-Dawlatly AA: Endoscopic Third Ventriculostomy: Anesthetic Implications. Minim Invasive Neurosurg 47:151-153, 2004

16. Etus V, Ceylan S: Success of endoscopic third ventriculostomy in children less than 2 years of age. Neurosurg Rev 28 : 284-288, 2005 
17. Fàbregas N, López A, Valero R, Carrero E, Caral L, Ferrer E: Anesthetic management of surgical neuroendoscopies: Usefulness of monitoring the pressure inside the neuroendoscope. J Neurosurg Anesthesiol 12: 21-28, 2000

18. Feng $\mathrm{H}$, Huang G, Liao X, Fu K, Tan H, Pu H, Cheng Y, Liu W, Zhao D: Endoscopic third ventriculostomy in the management of obstructive hydrocephalus: An outcome analysis. J Neurosurg 100: 626-633, 2004

19. Fukuhara T, Vorster SJ, Luciano MG: Risk factors for failure of endoscopic third ventriculostomy for obstructive hydrocephalus. Neurosurgery 46: 1100-1109, 2000

20. Gorayeb RP, Cavalheiro S, Zymberg ST: Endoscopic third ventriculostomy in children younger than 1 year of age. J Neurosurg 100: 427-429, 2004

21. Hume-Smith H, McCormack J, Montgomery C, Brant R, Malherbe S, Mehta D, Ansermino JM: The effect of age on the dose of remifentanil for tracheal intubation in infants and children. Paediatr Anaesth 20: 19-27, 2010

22. Javadpour M, Mallucci C, Brodbelt A, Golash A, May P: The impact of endoscopic third ventriculostomy on the management of newly diagnosed hydrocephalus in infants. Pediatr Neurosurg 35: 131-135, 2001

23. Jones RF, Stening WA, Brydon M: Endoscopic third ventriculostomy. Neurosurgery 26: 86-92, 1990

24. Jones RF, Kwok BC, Stening WA, Vonau M: Third ventriculostomy for patients with spinal dysraphism: Indications and contraindications. Eur J Pediatr Surg 6 (Suppl) 1: 5-6, 1996
25. Leach P, Thorne J, Palmer J: Response to: Ten years experience with paediatric neuroendoscopic third ventriculostomy features and perioperative complications of 210 cases. J Neurosurg Anesthesiol 17:172, 2005

26. Mclaughlin MR, Wahling JB, Kaufman AM: Traumatic basilar aneurysm after endoscopic third ventriculostomy: Case report. Neurosurgery 41:1400-1404, 1997

27. Michel F, Lando A, Aubry C, Arnaud S, Merrot T, Martin $C$ : Experience with remifentanil-sevoflurane balanced anesthesia for abdominal surgery in neonates and children less than 2 years. Paediatr Anaesth 18: 532-538, 2008

28. Schmidt J, Hunsicker A, Irouschek A, Köhler H, Knorr C, Birkholz T: Early recovery from anesthesia and extubation in an infant with very long chain acyl-CoA dehydrogenase deficiency using midazolam, mivacurium, and high dose remifentanil. Paediatr Anaesth 19: 909-910, 2009

29. Standing JF, Hammer GB, Sam WJ, Drover DR: Pharmacokinetic-pharmacodynamic modeling of the hypotensive effect of remifentanil in infants undergoing cranioplasty. Paediatr Anaesth 20: 7-18, 2010

30. van Aken J, Struys M, Verplancke T, de Baerdemaeker L, Caemaert J, Mortier E: Cardiovascular changes during endoscopic third ventriculostomy. Minim Invas Neurosurg 46: 198-201, 2003 